\title{
Circulatory Effects of Inhaled Iloprost in the Newborn Preterm Lamb
}

\author{
TOMMI NOPONEN, ANDERS NORDH, ANSGAR BERG, DAVID LEY, STEFAN R. HANSSON, ERKKI PESONEN, \\ AND VINETA FELLMAN
}

\begin{abstract}
Departments of Pediatrics [A.N., D.L., E.P., V.F.] and Obstetrics and Gynecology [S.H.], Lund University, Lund 22185, Sweden; Turku PET Center [T.N.], Turku University Hospital, Turku 20521, Finland; Department of Biomedical Engineering and Computational Science [T.N.], Helsinki University of Technology, Espoo 02015, Finland; Section for Pediatrics [A.B.], University of Bergen, Bergen, Norway; Department of Pediatrics [V.F.], University of Helsinki, Helsinki 00014, Finland
\end{abstract}

\begin{abstract}
Inhaled NO (iNO) has an established role in the treatment of pulmonary hypertension $(\mathrm{PH})$ in the newborn. However, costs and potential toxicity associated with iNO have generated interest in alternative inhaled selective pulmonary vasodilators such as iloprost. In a preterm lamb model of respiratory distress syndrome, we studied effects of increasing doses of iloprost followed by iNO on right ventricular pressure (RVP) and circulation including cerebral oxygenation. Fetal sheep were randomized to three doses $(0.2-4$ $\mathrm{mg} / \mathrm{kg})$ of iloprost $(n=9)$ or saline $(n=10)$, administered as 15-min inhalations with 15 -min intervals after a 60 -min postnatal stabilization. No differences were found in RVP, arterial $\mathrm{PO}_{2}$, or cardiac index according to treatment. The cerebral oxygenation, measured with near-infrared spectroscopy, deteriorated in control lambs, but not in iloprost lambs. Iloprost treatment followed by iNO resulted in a larger decrease $(p=0.007)$ in RVP than saline treatment followed by iNO. In conclusion, iloprost stabilized cerebral oxygenation and when followed by iNO had a larger effect on RVP than iNO alone. Although species differences may be relevant, these results suggest that iloprost should be studied in newborn infants for the treatment of PH. (Pediatr Res 66: 416-422, 2009)
\end{abstract}

$\mathrm{D}$ uring normal postnatal transition from fetal to neonatal circulation, the pulmonary vascular resistance decreases rapidly. The vascular tone in pulmonary arteries is regulated by a balance of vasoconstrictors and vasodilators. Endothelin, hypoxemia, and acidemia have strong constrictor effects on pulmonary arterioles (1). The main endogenous vasodilators are the endothelial-derived substances NO and prostacyclin, which increase endothelial cell production of cGMP and cAMP, respectively (1). When the transition is disturbed, the pulmonary arterial resistance remains elevated resulting in considerable hypoxemia and low-oxygen delivery to tissue. As arterial $\mathrm{O}_{2}$ tension does not necessarily reflect the oxygen delivery to tissue because of low perfusion or extraction, near-infrared spectroscopy (NIRS) has been applied to monitoring tissue oxygenation (2).

Inhaled NO (iNO) exerts a rapid pulmonary vasodilatation and is an established treatment of pulmonary hypertension $(\mathrm{PH})$ in newborn infants (3). iNO has, however, several dis-

Received January 5, 2009; accepted June 9, 2009

Correspondence: Vineta Fellman, M.D., Ph.D., Division of Pediatrics, Lund University, SE-22185 Lund, Sweden; e-mail vineta.fellman@med.lu.se

Supported with grants from University Hospital in Lund (Region Skåne) and Medical Faculty of Lund University. advantages, such as unpredictable and nonsustained effect, and rebound PH after withdrawal (4). The toxic NO product peroxynitrite inhibits prostacyclin synthase (5), the key enzyme of prostacyclin synthesis. Further, NO causes an increased endothelin-1 release (6). Thus, other effective agents with fewer side effects are sought for the treatment of PH in the newborn.

Prostanoids have been administered in the clinical setting mainly in adults as i.v. infusions of prostacyclin, s.c. infusion of treprostinil, and inhalations of iloprost (7). I.v. prostacyclin causes severe systemic hypotension in newborns (8). Inhaled prostacyclin decreases pulmonary vascular resistance without decreasing systemic blood pressure. The prostacyclin analogue iloprost has a longer half-life (almost $30 \mathrm{~min}$ ) than prostacyclin, and when administered as repetitive inhalations decreases PH in adults $(7,9)$. Iloprost has not been investigated in series of newborn infants, although case reports suggest that it is effective in this age group (10-12).

In newborn lambs, hypoxia results in pulmonary vasoconstriction leading to a condition similar to the persistent $\mathrm{PH}$ of the newborn (13). Delivering lambs at $126 \mathrm{~d}$ of gestation leads to severe RDS $(14,15)$, and preterm lambs with RDS have increased pulmonary vascular resistance (16). Newborn infants with RDS and need of supplementary oxygen, despite surfactant treatment have a component of increased pulmonary arterial resistance $(12,17,18)$ that may induce right ventricular (RV) failure. PH and RV failure may cause inadequate left ventricle filling, decreased cardiac output, and systemic hypotension (19).

The objective of this study was to test in our preterm lamb model (20) the hypothesis that inhaled iloprost decreases pulmonary vascular resistance and hypertension, and therefore increases pulmonary circulation with beneficial effects on cardiac output, systemic oxygen saturation, and cerebral oxygenation. A further aim was to assess the effects of additional iNO treatment.

Abbreviations: $\Delta$ cyto-ox, changes of cytochrome-c-oxidase; $\Delta\left[\mathbf{H b O}_{2}\right]$, changes of oxyhemoglobin; $\Delta[\mathbf{H b R}]$, changes of deoxyhemoglobin; DPF, differential path-length factor; iNO, inhaled NO; LCA, left coronary artery; NIRS, near-infrared spectroscopy; PH, pulmonary hypertension; RCA, right coronary artery; RV, right ventricular; RVP, right ventricular pressure; TOI, tissue oxygenation index 


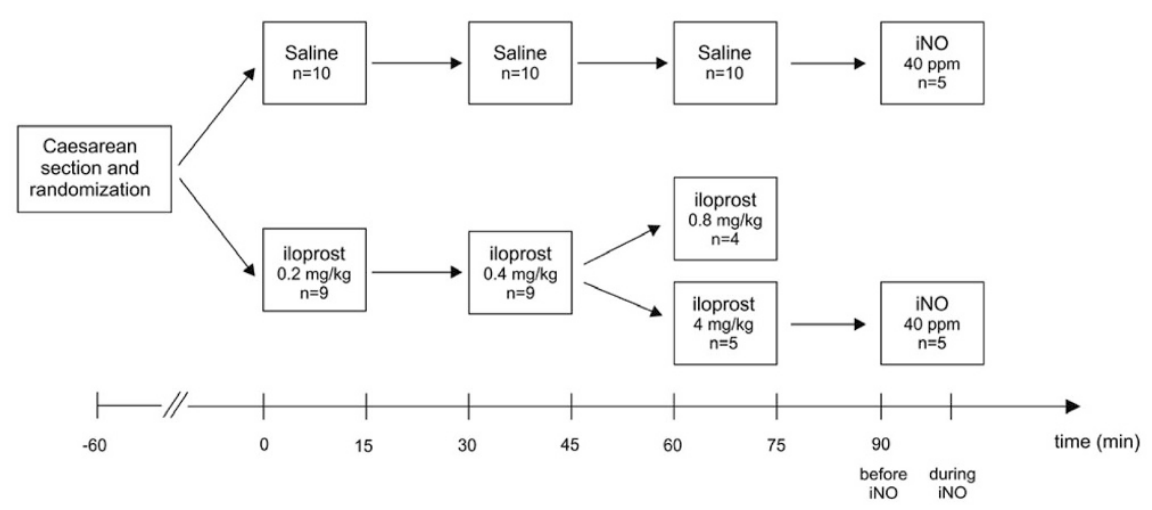

Figure 1. Randomization procedure of newborn sheep, allocated to iloprost or saline inhalations at birth. The duration of each inhalation was $15 \mathrm{~min}$ with a 15 -min interval. Three sequentially increasing iloprost doses were given with a 5-fold difference in the third dose between the subgroups. iNO was administered as indicated after 90-min time point.

\section{METHODS}

Animals. Twenty preterm fetal sheep of mixed breed and gender at a mean gestational age of $126 \mathrm{~d}$ (range 125-128; i.e. $87 \%$ of full-term $145 \mathrm{~d}$ ) and a weight of $2580 \pm 548 \mathrm{~g}$ (mean $\pm \mathrm{SD}$ ) were used. At delivery, the lamb was randomized using sealed envelopes to iloprost or control group (Fig. 1). One lamb died before randomization. The animal Research Ethics Committee of Lund University approved the study protocol.

Surgical procedure. The pregnant ewes were intubated after thiopental induction ( $225 \mathrm{mg}$, i.e. ca $3 \mathrm{mg} / \mathrm{kg}$ ), and cesarean section was performed during isoflurane anesthesia supplemented by opiate infusion (Fentanyl $150 \mu \mathrm{g}$, i.e. ca 2 $\mu \mathrm{g} / \mathrm{kg}$ ). After lower midline incision, the fetal head and neck were extracted through a small incision of the uterus. A rubber glove was placed over the head to preclude fetal breathing. Catheters were placed in the axillary artery and in the jugular vein for baseline blood sampling. An ultrasonic flow probe was placed on the carotid artery. An endotracheal tube was inserted by tracheotomy and excess of lung fluid was allowed to drain passively into a closed system. Intratracheal surfactant (100 mg/kg estimated fetal weight, Survanta, Abbott Laboratories) was given and then the tube was clamped. The lamb was delivered, weighed, and placed in an incubator. The ewe was kept anesthetized for delivery of the second lamb and suturation of the operation wound.

Study protocol. After delivery, the endotracheal tube was connected to the ventilator Servo 300 (Siemens-Elema, Solna, Sweden) with pressureregulated ventilation using inspiratory pressure of $25 \mathrm{~cm} \mathrm{H}_{2} \mathrm{O}$, positive-end expiratory pressure of $4 \mathrm{~cm} \mathrm{H}_{2} \mathrm{O}$, and fixed inhaled oxygen gas mixture of $40 \%$. Although the settings were adjustable to achieve and maintain an arterial $\mathrm{CO}_{2}$ pressure $\left(\mathrm{PaCO}_{2}\right)$ of $4.5-6 \mathrm{kPa}$, the initial settings remained unchanged in all lambs. Sedation and analgesia were maintained with i.v. fentanyl infusion of $10 \mu \mathrm{g} / \mathrm{kg} / \mathrm{h}$ after a loading dose of $20 \mu \mathrm{g} / \mathrm{kg}$. Fentanyl was dissolved in $5 \%$ glucose solution in a concentration resulting in a fluid infusion rate of $3 \mathrm{ml} / \mathrm{kg} / \mathrm{h}$. Through the jugular vein, a catheter was inserted under ultrasound guidance into the right ventricle for pulmonary pressure estimates from the typical curve of right ventricular pressure (RVP). The umbilical vein and artery (for postductal blood sampling) were catheterized. ECG was recorded with three s.c. electrodes. On the scalp, a temperature probe and the NIRS probe of NIRO 300 (Hamamatsu Photonics, Hamamatsu, Japan) were attached. A continuous tail pulse oximetry (Nellcor N-395, Nellcor Puritan Bennet Inc., Pleasanton, CA) was used.

The randomization was blinded to all except one researcher responsible for the administration of inhalations (AN). At 60 min of ventilation and stabilization, the nebuliser (Siemens Servo Ultra Nebulizer 345) was attached to the ventilator tubing close to the endotracheal tube, and inhalations were given over a 15 -min period for each iloprost dose, with a 15-min interval between inhaled doses. Saline was added to the nebuliser and administered at the corresponding time points in the control group. The dose of iloprost was doubled for each inhalation in the low-dose group, whereas the last increase was 5-fold in the high-dose group compared with that in the low-dose group. High-dose iloprost and five control lambs received iNO of $40 \mathrm{ppm}$ starting after $90 \mathrm{~min}$ (Fig. 1).

Recordings and measurements. Systemic arterial blood pressure and RVP were continuously monitored through the inserted catheters. Heart rate and ECG were recorded and displayed continuously. Peripheral oxygen saturation was registered every $15 \mathrm{~min}$. Transthoracic echocardiography was performed every 15 min during the experiment using a Siemens Acuson Sequoia C 512 echocardiography system (Siemen AG, Germany). Blood flow velocities in the aorta and proximal parts of the coronary arteries were registered with 10 MHz pulsed wave Doppler ultrasound probe. The angle between the Doppler beam and the longitudinal axis of the vessel was kept as small as possible and always less than $30^{\circ}$. A sample volume that gave the best possible quality and pure sonic signal throughout the cardiac cycle was chosen. Cardiac output was estimated as velocity time integral multiplied by the cross-sectional area and heart rate. All ultrasonic measurements were stored on magneto-optic discs and measurements of Doppler velocities and time integrals were performed off-line with the analysis package of the ultrasound unit.

Arterial preductal and postductal blood was sampled in 15-min intervals for measuring $\mathrm{pH}$ and blood gases [arterial $\mathrm{O}_{2}\left(\mathrm{PaO}_{2}\right)$ and $\mathrm{CO}_{2}$ pressure $\left(\mathrm{PaCO}_{2}\right)$ with ABL 300 Radiometer, Copenhagen, Denmark]. Measurements were corrected for ovine species according to a factory-installed algorithm and for actual temperature.

For NIRS monitoring, the fetal head was shaved and cleaned, and the probe was attached above the temporal lobe. The probe provides alternative 4- and 5-cm distances for NIRS measurements. The longer distance was preferred to maximize the contribution of cerebral signal. In five lambs with small head, the 4-cm distance was used. The signals, which were related to the concentration changes of oxyhemoglobin $\left(\Delta\left[\mathrm{HbO}_{2}\right]\right)$ and deoxyhemoglobin $(\Delta[\mathrm{HbR}])$, the redox-state changes of cytochrome-c-oxidase ( $\Delta$ cyto-ox), and tissue oxygenation index (TOI) were measured and acquired into the adjacent computer at $0.2 \mathrm{~Hz}$ sampling rate for off-line data processing. The TOI signal represents a mixture of dominantly a venous and less arterial blood oxygen saturation [2]. One NIRS recording in the low-iloprost dose group was discarded because of technical problems and one during iNO because of movement artifacts.

Responses to iloprost treatment were measured 15 and $30 \mathrm{~min}$ after the onset of each inhalation, the 30-min measurements obtained immediately before the next inhalation, in total seven time points. The 90-min values were used as baseline for iNO (before iNO), and the response values (during iNO) were obtained within the next $10 \mathrm{~min}$. NIRS values were extracted at every 15 min concurrent with other parameters. If the contact of NIRS probe was substantially loosened, the TOI signal obtained zero values. The artifact data during these intervals were removed from all the NIRS signals. Also, sudden changes in the NIRS signals caused by variations in the contact between the NIRS probe and the head were corrected with an algorithm. In addition, noise was reduced in the NIRS signals with a sliding four-time points long median filtering. Signals were divided with the product of geometrical distance between NIRS source and detector, and the differential path-length factor (DPF) to obtain the quantitative units for $\Delta\left[\mathrm{HbO}_{2}\right]-, \Delta[\mathrm{HbR}]-$, and $\Delta$ cyto-ox. We used DPF $=4.55$ as previously used for fetal lambs (21). Concentration changes of total $\mathrm{Hb}\left(\Delta[\mathrm{totHb}]=\Delta\left[\mathrm{HbO}_{2}\right]+\Delta[\mathrm{HbR}]\right)$ were also analyzed. Relative TOI values were derived by normalizing the original TOI signal with its baseline value before the first iloprost or saline inhalation or iNO. These time points were selected as baseline points for $\Delta\left[\mathrm{HbO}_{2}\right]-, \Delta[\mathrm{HbR}]-$, and $\Delta$ cyto-oxsignals. Baseline NIRS values were obtained during a period from 4 to 2 min before iNO and during iNO values 8 to $10 \mathrm{~min}$ after initiation of iNO.

Statistical methods. The data preprocessing and statistical analyses were carried out in MATLAB programming environment (The MathWorks, Inc.) and in addition with SPSS software version 15.0 (SPSS, Inc.) for the repeated measures ANOVA. The normality of values was verified with the Bera-Jarque parametric hypothesis test. The group differences between iloprost and saline lambs at 0 and $30 \mathrm{~min}$ were tested using the unpaired two-tailed $t$ test with Bonferroni correction. Unpaired $t$ test was applied with equal or unequal variances after the variance equality was tested using the two-sample $\mathrm{F}$ test. With repeated measures ANOVA the differences were tested between the two groups from baseline until $60 \mathrm{~min}$, and between the three groups from 60 to 90 min. Games-Howell posthoc test was used to test which pairs had significant differences. The effect of the total iloprost treatment was assessed as from baseline and the midpoint $45 \mathrm{~min}$ to the end $90 \mathrm{~min}$. The low- and high-iloprost groups were combined for these tests, and the group difference between iloprost and saline was tested using the unpaired two-tailed $t$ test with Bonferroni correction because of two partly overlapping test periods. Re- 
Table 1. Blood gases, cardiovascular parameters, and cerebral near-infrared spectroscopy results in lambs randomized to inhalation with saline (control group) or increasing doses of Iloprost (0.2 and $0.4 \mathrm{mg} / \mathrm{kg}$, respectively over $15 \mathrm{~min}$ with a 15-min interval, followed by a third dose of 0.8 or $4 \mathrm{mg}$ in low and high subgroups, respectively, see Fig. 1)

\begin{tabular}{|c|c|c|c|c|c|}
\hline & \multicolumn{3}{|c|}{ Baseline } & \multicolumn{2}{|c|}{$30 \mathrm{~min}$} \\
\hline & \multicolumn{2}{|c|}{$\begin{array}{l}\text { Control } \\
(n=10)\end{array}$} & $\begin{array}{l}\text { iloprost } \\
(n=9)\end{array}$ & $\begin{array}{l}\text { Control } \\
(n=10)\end{array}$ & $\begin{array}{c}\text { iloprost, } 0.2 \\
(n=9)\end{array}$ \\
\hline Hemoglobin $(\mathrm{g} / \mathrm{l})$ & \multicolumn{2}{|c|}{$157 \pm 3 \dagger$} & $145 \pm 5$ & $153 \pm 3$ & $138 \pm 5 \| \neq$ \\
\hline $\mathrm{pH}$ & \multicolumn{2}{|c|}{$7.39 \pm 0.05 \dagger$} & $7.36 \pm 0.04$ & $7.44 \pm 0.05$ & $7.39 \pm 0.05$ \\
\hline $\mathrm{BE}$ & \multicolumn{2}{|c|}{$-2.2 \pm 2.8 \dagger$} & $-2.3 \pm 1.5$ & $-1.0 \pm 2.4$ & $-1.6 \pm 1.3 \ddagger$ \\
\hline $\mathrm{PaCO}_{2}$, preductal $(\mathrm{kPa})$ & \multicolumn{2}{|c|}{$4.9 \pm 0.3 \dagger$} & $5.5 \pm 0.4$ & $4.4 \pm 0.3$ & $5.4 \pm 0.8$ \\
\hline $\mathrm{PaCO}_{2}$, postductal $(\mathrm{kPa})$ & \multicolumn{2}{|c|}{$5.0 \pm 0.3$} & $5.5 \pm 0.5$ & $4.5 \pm 0.3$ & $5.4 \pm 0.8$ \\
\hline $\mathrm{PaO}_{2}$, preductal $(\mathrm{kPa})$ & \multicolumn{2}{|c|}{$3.8 \pm 0.5 \dagger$} & $5.0 \pm 1.1$ & $4.4 \pm 0.5$ & $4.1 \pm 0.8 \ddagger$ \\
\hline $\mathrm{PaO}_{2}$, postductal $(\mathrm{kPa})$ & \multicolumn{2}{|c|}{$4.1 \pm 0.5$} & $5.8 \pm 1.5$ & $4.4 \pm 0.5$ & $4.1 \pm 0.7$ \\
\hline $\mathrm{SaO}_{2}$, preductal $(\%)$ & \multicolumn{2}{|c|}{$85 \pm 3 \dagger$} & $87 \pm 4$ & $88 \pm 2$ & $85 \pm 4 \ddagger$ \\
\hline $\mathrm{SaO}_{2}$, postductal $(\%)$ & \multicolumn{2}{|c|}{$88 \pm 2$} & $88 \pm 4$ & $88 \pm 2$ & $83 \pm 5$ \\
\hline Systolic arterial blood pressure, $\mathrm{mm} \mathrm{Hg}$ & \multicolumn{2}{|c|}{$80 \pm 3$} & $79 \pm 6$ & $73 \pm 4$ & $70 \pm 4$ \\
\hline Right ventricular pressure, $\mathrm{mm} \mathrm{Hg}$ & \multicolumn{2}{|c|}{$58.5 \pm 4.5$} & $57.6 \pm 5.1$ & $50.7 \pm 4.0$ & $52.5 \pm 4.6$ \\
\hline $\mathrm{CI}, 1 / \mathrm{min} / \mathrm{m}^{2}$ & \multicolumn{2}{|c|}{$5.0 \pm 0.2$} & $4.5 \pm 0.3$ & $4.3 \pm 0.4$ & $4.0 \pm 0.4$ \\
\hline $\mathrm{CO}, \mathrm{ml} / \mathrm{min} / \mathrm{kg}$ & \multicolumn{2}{|c|}{$1040 \pm 55$} & $950 \pm 65$ & $885 \pm 70$ & $815 \pm 85$ \\
\hline Carotid flow, $\mathrm{ml} / \mathrm{min}$ & $13.5 \pm$ & & $13.7 \pm 2.9$ & $13.5 \pm 2.0 \dagger$ & $14.9 \pm 3.1$ \\
\hline TOI $(\%)$ & $54 \pm$ & & $44 \pm 3$ & $54 \pm 3$ & $43 \pm 3 \|$ \\
\hline & & & & $90 \mathrm{~min}$ & \\
\hline & $\begin{array}{l}\text { Control } \\
(n=10)\end{array}$ & $\begin{array}{l}\text { iloprost, } 0.4 \\
\quad(n=9)\end{array}$ & $\begin{array}{l}\text { Control } \\
(n=10)\end{array}$ & $\begin{array}{l}\text { iloprost, low } \\
\quad(n=4)\end{array}$ & $\begin{array}{l}\text { iloprost, high } \\
\quad(n=5)\end{array}$ \\
\hline Hemoglobin $(\mathrm{g} / \mathrm{l})$ & $150 \pm 3$ & $134 \pm 4 *+$ & $148 \pm 3$ & $135 \pm 8$ & $129 \pm 3^{* *}$ \\
\hline $\mathrm{pH}$ & $7.44 \pm 0.05$ & $7.37 \pm 0.03 \ddagger$ & $7.39 \pm 0.05$ & $7.27 \pm 0.09$ & $7.36 \pm 0.04$ \\
\hline $\mathrm{BE}$ & $-0.6 \pm 2.4$ & $-1.3 \pm 1.0 \ddagger$ & $-1.8 \pm 2.2$ & $-8.2 \pm 3.0$ & $0.2 \pm 1.2$ \\
\hline $\mathrm{PaCO}_{2}$, preductal $(\mathrm{kPa})$ & $4.5 \pm 0.3$ & $5.8 \pm 0.7 \ddagger$ & $5.3 \pm 0.5$ & $5.8 \pm 1.4$ & $6.3 \pm 0.7$ \\
\hline $\mathrm{PaCO}_{2}$, postductal $(\mathrm{kPa})$ & $4.6 \pm 0.3$ & $5.9 \pm 0.5$ & $5.2 \pm 0.5$ & $6.1 \pm 1.4$ & $6.5 \pm 0.9$ \\
\hline $\mathrm{PaO}_{2}$, preductal $(\mathrm{kPa})$ & $4.2 \pm 0.6$ & $3.9 \pm 0.5 \$$ & $3.8 \pm 0.7$ & $2.4 \pm 0.5$ & $4.6 \pm 0.9$ \\
\hline $\mathrm{PaO}_{2}$, postductal $(\mathrm{kPa})$ & $4.4 \pm 0.6$ & $3.6 \pm 0.6$ & $3.7 \pm 0.7$ & $2.3 \pm 0.5$ & $4.4 \pm 0.9$ \\
\hline $\mathrm{SaO}_{2}$, preductal $(\%)$ & $82 \pm 5$ & $81 \pm 5 \neq$ & $69 \pm 10$ & $58 \pm 13$ & $83 \pm 6$ \\
\hline $\mathrm{SaO}_{2}$, postductal $(\%)$ & $83 \pm 5$ & $75 \pm 8$ & $68 \pm 10$ & $54 \pm 15$ & $82 \pm 7$ \\
\hline Systolic arterial blood pressure, $\mathrm{mm} \mathrm{Hg}$ & $66 \pm 4 \dagger$ & $64 \pm 5$ & $70 \pm 6 \dagger$ & $66 \pm 8$ & $72 \pm 8$ \\
\hline Right ventricular pressure, $\mathrm{mm} \mathrm{Hg}$ & $44.4 \pm 2.1$ & $47.6 \pm 4.9$ & $42.4 \pm 2.6 \dagger$ & $60.7 \pm 10.6 \S$ & $46.8 \pm 3.3$ \\
\hline $\mathrm{CI}, 1 / \mathrm{min} / \mathrm{m}^{2}$ & $3.6 \pm 0.4$ & $3.6 \pm 0.5$ & $3.5 \pm 0.4$ & $3.4 \pm 0.6$ & $4.5 \pm 0.7$ \\
\hline $\mathrm{CO}, \mathrm{ml} / \mathrm{min} / \mathrm{kg}$ & $735 \pm 75$ & $750 \pm 100$ & $724 \pm 84$ & $652 \pm 112$ & $984 \pm 199$ \\
\hline Carotid flow, $\mathrm{ml} / \mathrm{min}$ & $12.8 \pm 2.3 \dagger$ & $17.0 \pm 3.1$ & $15.8 \pm 2.9 \dagger$ & $24.3 \pm 8.8$ & $16.0 \pm 2.5$ \\
\hline TOI $(\%)$ & $45 \pm 3 \dagger$ & $42 \pm 3 *$ & $37 \pm 5 \dagger$ & $41 \pm 5 \S$ & $42 \pm 5$ \\
\hline
\end{tabular}

$\mathrm{BE}$, base excess; CI, cardiac index; $\mathrm{CO}$, cardiac output.

Significant differences between groups over time periods 0-60 and 60-90 min, respectively, are indicated with * $p<0.05$, ** $p<0.01$ (analyzed with repeated measures ANOVA) and at time point 30 min with $\| p<0.025$ (analyzed with $t$ test). When values missing, indicated with: $\dagger n=9$, $\ddagger n=8$, and $\S n=3$ ). Measurements were performed at 30, 60, and 90 min before the next inhalation (see Methods, Fig. 1).

sponse to iNO was tested using the paired two-tailed $t$ test, and group differences with the unpaired two-tailed $t$ test. A $p$ value $<0.05$ was considered significant and when Bonferroni correction was applied $<0.025$. Data are presented as group means and SEM.

\section{RESULTS}

Mean values of parameters in iloprost and control lambs at baseline and at $30 \mathrm{~min}$ intervals are presented in Table 1. At baseline, the difference in $\mathrm{Hb}$ concentration and TOI between the groups was not significant, whereas both parameters were significantly lower in the iloprost group at $30 \mathrm{~min}(p<0.025)$. Remaining parameters did not differ between the groups, neither at baseline nor at $30 \mathrm{~min}$.

Repeated measures ANOVA showed a significant difference between the groups in $\mathrm{Hb}(p=0.021)$ and TOI $(p=$ 0.050 ) at baseline until $60 \mathrm{~min}$ (Table 1), whereas changes over time $(0-60 \mathrm{~min})$ in any parameters did not differ between groups. Within both groups, $\mathrm{Hb}(p<0.001)$, TOI $(p=0.017)$, relative TOI $(p=0.027)$, and RVP $(p=0.004)$ decreased significantly from baseline to $60 \mathrm{~min}$. A similar gradual decrease ( $p<0.001$ for all parameters in both groups) was found in cardiac output, cardiac index, systolic and diastolic blood pressure (Table 1) and in $\Delta\left[\mathrm{HbO}_{2}\right]$ and $\Delta$ [totHb] (Fig. 2).

The third iloprost dose had no evident effect on physiologic parameters. Hb differed between the high-dose treatment and vehicle groups over the time period of 60-90 min (Table 1). $\mathrm{Hb}$ values continued to decrease significantly $(p<0.05)$ in all groups over 60-90 min. No significant decrease in RVP were found in response to iloprost (range $30-60 \mathrm{~mm} \mathrm{Hg}$ in high dose and $40-77 \mathrm{~mm} \mathrm{Hg}$ in low-dose lambs) compared with controls (range $24-54 \mathrm{~mm} \mathrm{Hg}$ ), whereas systolic blood pressure increased $(p<0.05)$ in all groups over 60-90 min (Table 1). NIRS values were similar in the low- and high-iloprost groups (Fig. 2). In control lambs from time point $45 \mathrm{~min}$ to 90 min, a significant decrease $(p<0.025)$ occurred in $\Delta\left[\mathrm{HbO}_{2}\right]$ and in relative TOI, whereas no such change occurred in the iloprost treated animals with low- and high-dose groups com- 
A

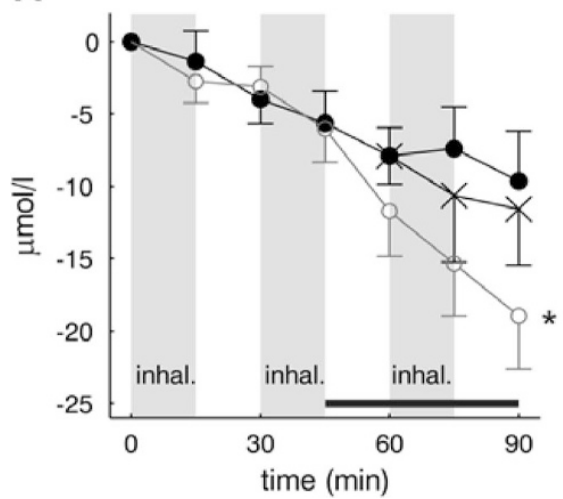

B

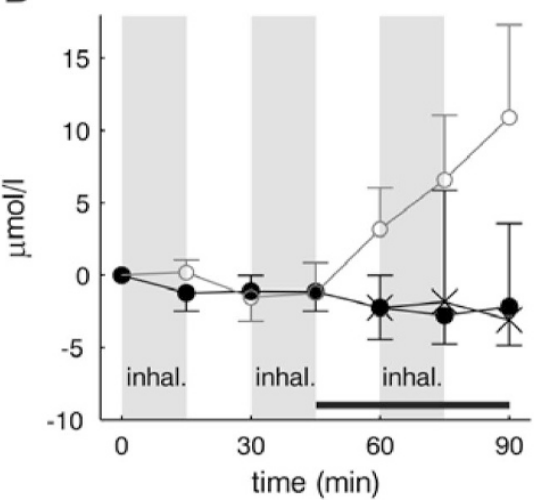

C

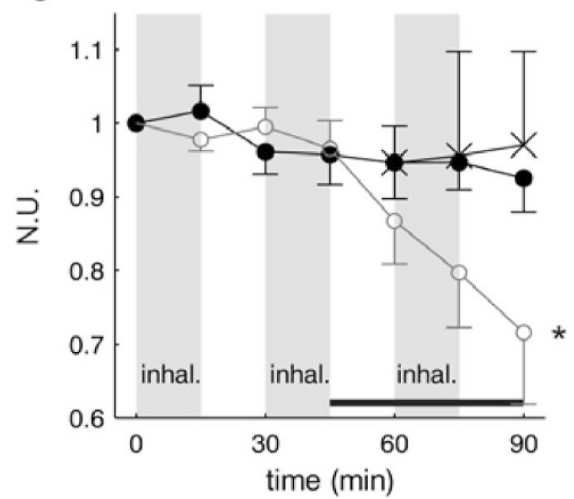

Figure 2. Effect of iloprost inhalations (gray areas) on cerebral tissue oxygenation. Symbols indicate: $\bigcirc$ saline $(n=10), \times$ low iloprost $(n=3)$, and $\bullet$ high iloprost $(n=5)$. The deterioration of oxygenation in control lambs observed as $(A)$ a decrease in $\Delta\left[\mathrm{HbO}_{2}\right],(C)$ a decrease in relative TOI [normalized unit (N.U.)], and $(B)$ an increase in $\Delta[\mathrm{HbR}]$ did not occur in iloprost lambs. The responses were similar to low- and high-iloprost doses. The changes of $\Delta\left[\mathrm{HbO}_{2}\right]$ and relative TOI from 45 to $90 \mathrm{~min}$ (solid thick line) were significantly $\left({ }^{*} p<0.025\right)$ different between control and iloprost lambs.

Table 2. Blood gases, oxygen saturation, and cardiac output (CO) before and during inhalation with 40 ppm of nitric oxide (iNO) in lambs pretreated with saline (control) or iloprost

\begin{tabular}{|c|c|c|c|c|}
\hline & $\begin{array}{c}\text { Before iNO } \\
\text { Control }(n=5)\end{array}$ & $\begin{array}{l}\text { During iNO } \\
\text { Control }\end{array}$ & $\begin{array}{c}\text { Before iNO } \\
\text { Iloprost }(n=5)\end{array}$ & $\begin{array}{l}\text { During iNO } \\
\text { Iloprost }\end{array}$ \\
\hline $\mathrm{pH}$, preductal & $7.38 \pm 0.05$ & $7.25 \pm 0.06^{*}$ & $7.40 \pm 0.04$ & $7.30 \pm 0.02 *$ \\
\hline $\mathrm{pH}$, postductal & $7.38 \pm 0.05$ & $7.25 \pm 0.06 \dagger$ & $7.39 \pm 0.04$ & $7.30 \pm 0.02$ \\
\hline $\mathrm{BE}$, preductal & $-0.9 \pm 2.0$ & $-4.2 \pm 2.3 \dagger$ & $0.2 \pm 0.8$ & $-1.9 \pm 0.6^{*}$ \\
\hline $\mathrm{BE}$, postductal & $-1.6 \pm 2.3$ & $-4.7 \pm 2.3 \dagger$ & $-0.4 \pm 0.9$ & $-2.2 \pm 0.7^{*}$ \\
\hline $\mathrm{PaCO}_{2}$, preductal $(\mathrm{kPa})$ & $5.5 \pm 0.6$ & $7.6 \pm 0.9^{*}$ & $5.4 \pm 0.6$ & $6.8 \pm 0.4^{*}$ \\
\hline $\mathrm{PaCO}_{2}$, postductal $(\mathrm{kPa})$ & $5.2 \pm 0.4$ & $7.4 \pm 0.7 *$ & $5.5 \pm 0.6$ & $6.9 \pm 0.5$ \\
\hline $\mathrm{PaO}_{2}$, preductal $(\mathrm{kPa})$ & $4.2 \pm 1.2$ & $11.8 \pm 2.8^{*}$ & $5.2 \pm 1.7$ & $12.8 \pm 2.4 \dagger$ \\
\hline $\mathrm{PaO}_{2}$, postductal $(\mathrm{kPa})$ & $4.3 \pm 1.3$ & $10.7 \pm 2.8^{*}$ & $4.9 \pm 1.5$ & $13.3 \pm 2.1 \dagger$ \\
\hline $\mathrm{SaO}_{2}$, postductal $(\%)$ & $68 \pm 16$ & $94 \pm 3$ & $81 \pm 7$ & $97 \pm 1$ \\
\hline Tail $\mathrm{SpO}_{2}(\%)$ & $66 \pm 17$ & $92 \pm 3$ & $84 \pm 8$ & $99 \pm 1$ \\
\hline $\mathrm{CO}, \mathrm{ml} / \mathrm{kg} / \mathrm{min}$ & $777 \pm 107$ & $997 \pm 127^{*}$ & $783 \pm 100$ & $992 \pm 51^{*}$ \\
\hline
\end{tabular}

Significant changes in response to iNO within respective group are marked $* p<0.05$ and $\dagger p<0.01$. No significant differences in responses between the groups were found.

$\mathrm{BE}$, base excess.

A

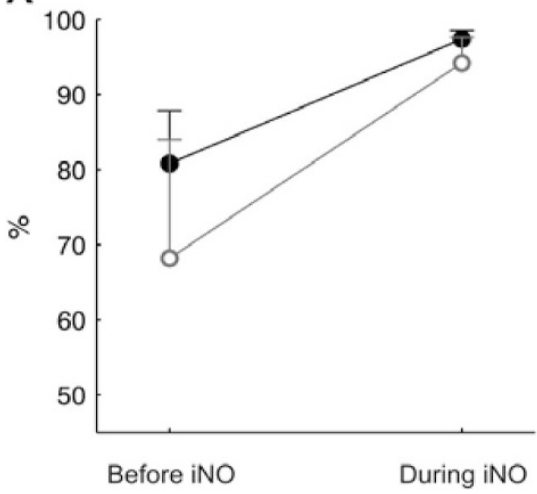

B

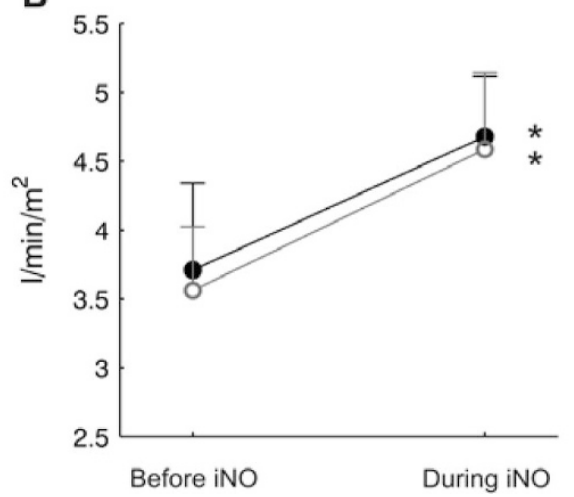

C

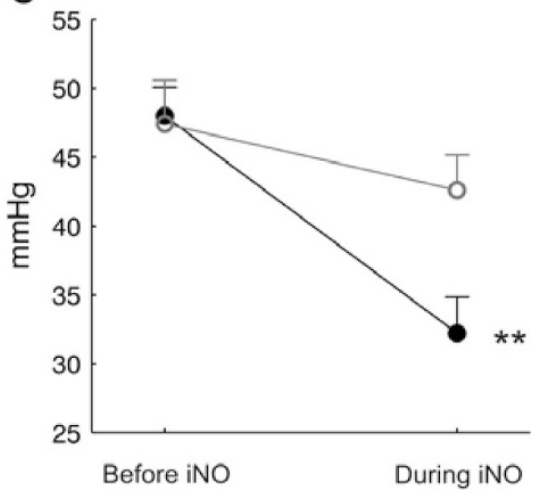

Figure 3. Changes of $(A)$ preductal arterial blood oxygen saturation (nonsignificant) and $(B)$ cardiac index $(* p<0.05)$ in response to iNO was similar in iloprost animals as in controls $(\bigcirc$ saline $+\mathrm{iNO}, n=5$ and - iloprost $+\mathrm{iNO}, n=5)$. $(C)$ The decrease of RVP was larger in iloprost pretreated animals than in controls $(* * p<0.01)$.

bined (Fig. 2). The $\Delta[$ totHb] values correlated significantly $\left(\mathrm{R}^{2}=0.14, p<0.001\right)$ with $\mathrm{Hb}$ values over the entire treatment period $15-90 \mathrm{~min}$, but $\Delta\left[\mathrm{HbO}_{2}\right]$ did not.

During iNO treatment, a marked increase in oxygenation occurred in both groups. The significant changes of several parameters shown in Table 2 were similar in both groups.
However, in iloprost pretreated lambs the RVP decreased significantly more $(p=0.007)$ than in saline pretreated lambs (Fig. 3). In both groups, the right coronary artery (RCA) blood flow increased with no significant difference in the change between groups (Fig. 4). During iNO, the $\Delta\left[\mathrm{HbO}_{2}\right]$ increased and $\Delta[\mathrm{HbR}]$ decreased (Fig. 5). 


\section{DISCUSSION}

The applied experimental model mimics severe RDS with persistent pulmonary pressure in preterm human infants $(12,17,18)$. Hypoxemia in the premature lamb model is a result of several factors, the most important being decreased oxygen uptake due to surfactant deficiency, $\mathrm{PH}$, and intrapulmonary and extrapulmonary shunts $(4,13,19,22)$. Surfactant was administered before initiation of ventilation resembling prophylactic surfactant administration in human infants. All lambs were delivered preterm and had arterial hypoxemia on a fixed inhaled oxygen concentration of $40 \%$, characteristically for RDS and all developed $\mathrm{PH}$ as judged from the elevated RVP. Thus, the degree of PH as well as severity of RDS in lambs at this gestational age exceeds that of extremely preterm human infants in general.

During the first $45 \mathrm{~min}$ of low-dose iloprost treatment, no effects were observed on RVP or echocardiographic measures of PH compared with vehicle. However, the control lambs deteriorated gradually, whereas lambs receiving iloprost treatment, irrespective of dose, maintained their cerebral oxygenation. Thus, the main effect of iloprost was a lack of deterioration in NIRS values.

NIRS is a promising noninvasive method for monitoring oxygenation and hemodynamic changes in tissue $(2,23)$. In children with increased pulmonary vascular resistance due to congenital heart defects, NIRS was applied to assess the effect of sildenafil (24), a phosphodiesterase 5 inhibitor causing accumulation of cGMP and thus a prolongation of NO effect.
A

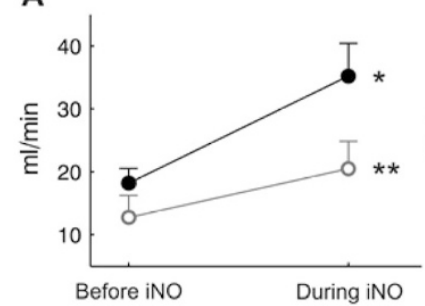

B

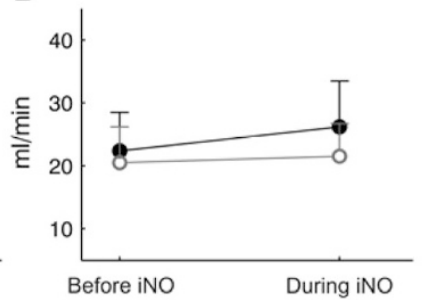

Figure 4. $A$, iNo increased the right coronary blood flow in both groups $\left({ }^{*} p<0.05, * * p<0.01\right)$, with no significant difference between the groups, whereas $(B)$ the left coronary blood flow was practically unchanged $(\bigcirc$ saline $+\mathrm{iNO}, n=4$, and $\bullet$ iloprost $+\mathrm{iNO}, n=5$ ).
An improvement of cerebral oxygenation was observed, suggesting that NIRS may be a valuable tool to assess effects in target organs (24).

Using the longest possible source to detector distance, which produces an appropriate signal level, the fraction of intracranial and extracranial hemodynamic changes can be maximized. The quantification of concentration signals depends on DPF values, which may vary $\pm 15 \%$ between individuals. We used DPF values previously published for fetal sheep (21). The NIRS parameters revealed significant changes between saline and iloprost groups, suggesting a beneficial effect of the iloprost on the cerebral oxygenation.

Increased prostacyclin concentrations in tracheal aspirates of preterm infants with RDS were associated with less severe disease suggesting a possible role of endogenous prostacyclin in alleviating the symptoms of RDS (25). In the majority of adult patients, a minor acute response to i.v. prostacyclin was found, although a more pronounced vasodilatation occurred during long-term therapy (26). In one study, iloprost was more effective in decreasing $\mathrm{PH}$ than iNO and sildenafil (27), whereas in another iNO was more effective than inhaled prostacyclin (28). For acute $\mathrm{PH}$, e.g. during cardiac surgery, iloprost had a beneficial effect both in adult and pediatric patients. Because it has a different site of action than NO and prevents lung damage in a model of neutrophil-induced lung injury (29), it would theoretically be a suitable treatment in the newborn infant (10). In adult patients with $\mathrm{PH}$, inhaled iloprost is recommended as a third or fourth-line agent or as an adjunct to i.v. prostacyclin therapy (30).

In the sheep lung, pulmonary prostacyclin production is enhanced in response to low-oxygen content (31), and the effect is more pronounced in newborn than older lambs $(11,32)$. Prostacyclin may have an additive vasodilatory effect to iNO on pulmonary arterioles. In this study, iloprost did not have the hypothesized beneficial effects on pulmonary vascular resistance as judged by RVP. However, the combination of iloprost and iNO was more effective than iNO alone.

With a half-life of 20-30 min, iloprost exerts pulmonary vasodilatory effects for a 30-90-min duration (7). In a newborn lamb study, iNO had a greater role than prostaglandins in pulmonary vasoregulation during acute hemodynamic stress
A

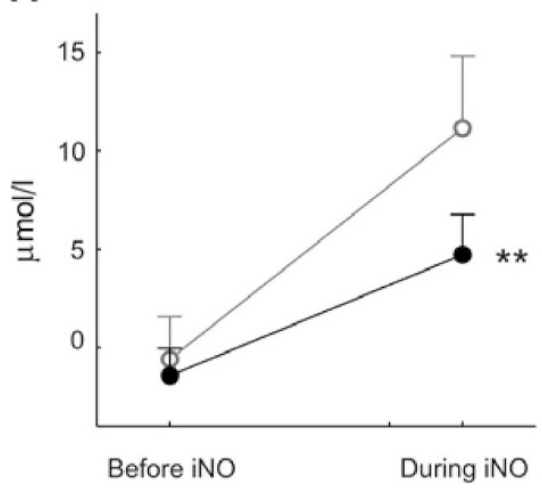

B

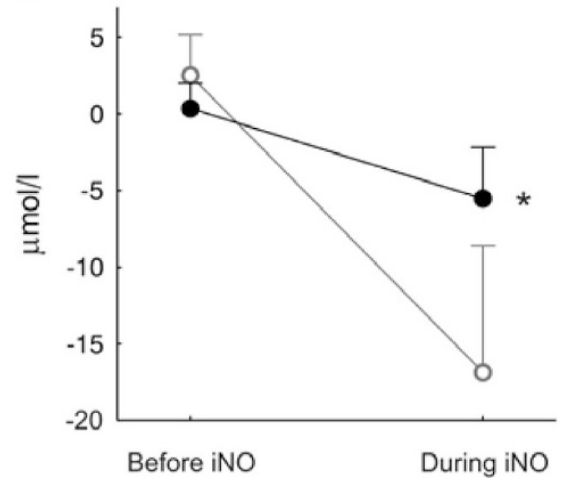

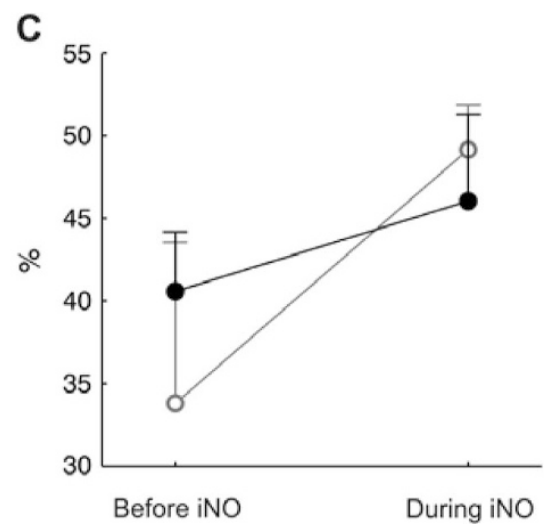

Figure 5. iNO treatment caused $(A)$ an increase in the $\Delta\left[\mathrm{HbO}_{2}\right]$ in control and iloprost groups with $(B)$ a corresponding decrease in $\Delta[\mathrm{HbR}], * p<0.05$, $* * p<$ 0.01. $C$, The increase in TOI after iNO was not significant $(\bigcirc$ saline $+\mathrm{iNO}, n=4$ and $\bullet$ iloprost $+\mathrm{iNO}, n=5)$. 
(33). Thus, the inferior effect of iloprost compared with that of iNO may be species specific.

Decrease of pulmonary vascular resistance and consequent decrease of RVP leads to decreased oxygen consumption in the myocardium (34). Therefore, RCA blood flow should decrease in concert with decreasing RV workload and oxygen consumption. However, in this study, RCA blood flow increased markedly with decreasing RVP in response to iNO. The left coronary artery (LCA) blood flow was less affected by iNO. After leaving the alveoli, the iNO is rapidly inactivated when exposed to $\mathrm{Hb}$ in the blood. However, because the coronary circulation is the first systemic vascular bed after the lungs, the dilating effect of exogenous NO on the RCA cannot be excluded. However, no such iNO effects have been observed previously $(35,36)$. A more plausible explanation for the observed increase in RCA flow is that a decrease in right ventricular intramural tension secondary to a reduction of right intraventricular systolic pressure facilitates coronary flow. In our recent study, we observed that increased RVP in newborn infants with critical pulmonary stenosis severely restricts RCA flow (37). The extravascular compression factor of total coronary resistance has been estimated as $29 \%$ of total coronary vascular resistance (38). The decrease in ventricular pressure leads to a decrease in the intramural tension. The near $50 \%$ increase of RCA flow observed seems partially due to a reduction in extravascular compression of myocardial capillaries. Increased flow through the lungs leads to augmented cardiac output, increased left ventricular oxygen demand, and consequently to increased LCA flow.

A limitation of the study was the small number of lambs, which restricted the possibility of detecting minor differences in iloprost effects between the groups. The somewhat lower $\mathrm{Hb}$ concentration in the iloprost group might have been a confounder resulting in a lower oxygen delivery with similar oxygen saturation in treated animals during the iloprost treatment. However, the trend of slightly higher values of carotid flow and $\mathrm{SaO}_{2}$ in the iloprost lambs than in controls before iNO might be a sign of a compensatory function, resulting in an increased oxygen delivery to the brain, reflected in the observed stabilization of NIRS values. Importantly, iloprost treatment resulted in a stabilized cerebral oxygenation in spite of lower $\mathrm{Hb}$ concentration.

In conclusion, the prostacyclin analog iloprost had a clearly inferior effect on pulmonary arterial pressure compared with iNO, whereas iloprost treatment preceding iNO seemed to augment the effect of iNO on RVP. This study supports the view that iNO and iloprost have beneficial additive effects when used in combination in newborns with severe hypoxia and increased pulmonary pressure. Thus, iloprost deserves to be investigated in newborn infants with this condition.

Acknowledgments. The authors thank the expert assistance of research nurses, Ann-Cathrine Berg, Ulla Ganestam, and Ingela Mattisson-Sandström, and thank Schering, Gothenburg Sweden for providing the drug (Ventavis).

\section{REFERENCES}

1. Fineman JR, Soifer SJ, Heymann MA 1995 Regulation of pulmonary vascular tone in the perinatal period. Annu Rev Physiol 57:115-134

2. Nagdyman N, Ewert P, Peters B, Miera O, Fleck T, Berger F 2008 Comparison of different near-infrared spectroscopic cerebral oxygenation indices with central venous and jugular venous oxygenation saturation in children. Paediatr Anaesth 18:160-166

3. Kinsella JP, Neish SR, Shaffer E, Abman SH 1992 Low-dose inhalation nitric oxide in persistent pulmonary hypertension of the newborn. Lancet 340:819-820

4. Oishi P, Grobe A, Benavidez E, Ovadia B, Harmon C, Ross GA, Hendricks-Munoz $\mathrm{K}, \mathrm{Xu}$ J, Black SM, Fineman JR 2006 Inhaled nitric oxide induced NOS inhibition and rebound pulmonary hypertension: a role for superoxide and peroxynitrite in the intact lamb. Am J Physiol Lung Cell Mol Physiol 290:L359-L366

5. Zou MH, Ullrich V 1996 Peroxynitrite formed by simultaneous generation of nitric oxide and superoxide selectively inhibits bovine aortic prostacyclin synthase. FEBS Lett 382:101-104

6. Earley S, Nelin LD, Chicoine LG, Walker BR 2002 Hypoxia-induced pulmonary endothelin-1 expression is unaltered by nitric oxide. J Appl Physiol 92:1152-1158

7. Olschewski H, Rose F, Schermuly R, Ghofrani HA, Enke B, Olschewski A, Seeger W 2004 Prostacyclin and its analogues in the treatment of pulmonary hypertension. Pharmacol Ther 102:139-153

8. Eronen M, Pohjavuori M, Andersson S, Pesonen E, Raivio KO 1997 Prostacyclin treatment for persistent pulmonary hypertension of the newborn. Pediatr Cardiol 18:3-7

9. Hoeper MM, Schwarze M, Ehlerding S, Adler-Schuermeyer A, Spiekerkoetter E, Niedermeyer J, Hamm M, Fabel H 2000 Long-term treatment of primary pulmonary hypertension with aerosolized iloprost, a prostacyclin analogue. N Engl J Med 342:1866-1870

10. Ehlen M, Wiebe B 2003 Iloprost in persistent pulmonary hypertension of the newborn. Cardiol Young 13:361-363

11. Lambert V, Serraf A, Durand P, Losay J 2001 [Aerosolized iloprost therapy in an infant with chronic pulmonary hypertension after a neonatal arterial switch operation]. Arch Pediatr 8:1218-1221

12. Olmsted K, Oluola O, Parthiban A, Raghuveer T 2007 Can inhaled prostacyclin stimulate surfactant in ELBW infants? J Perinatol 27:724-726

13. De Vroomen M, Steendijk P, Lopes Cardozo RH, Brouwers HH, Van Bel F, Baan J 2001 Enhanced systolic function of the right ventricle during respiratory distress syndrome in newborn lambs. Am J Physiol Heart Circ Physiol 280:H392-H400

14. Willet KE, Jobe AH, Ikegami M, Newnham J, Brennan S, Sly PD 2000 Antenatal endotoxin and glucocorticoid effects on lung morphometry in preterm lambs. Pediatr Res 48:782-788

15. Ingimarsson J, Bjorklund LJ, Curstedt T, Gudmundsson S, Larsson A, Robertson B, Werner O 2004 Incomplete protection by prophylactic surfactant against the adverse effects of large lung inflations at birth in immature lambs. Intensive Care Med 30:1446-1453

16. Sukumar M, Bommaraju M, Fisher JE, Morin FC III, Papo MC, Fuhrman BP, Hernan LJ, Leach CL 1998 High-frequency partial liquid ventilation in respiratory distress syndrome: hemodynamics and gas exchange. J Appl Physiol 84:327-334

17. Walther FJ, Benders MJ, Leighton JO 1992 Persistent pulmonary hypertension in premature neonates with severe respiratory distress syndrome. Pediatrics 90:899_ 904

18. Kinsella JP, Cutter GR, Walsh WF, Gerstmann DR, Bose CL, Hart C, Sekar KC, Auten RL, Bhutani VK, Gerdes JS, George TN, Southgate WM, Carriedo H, Couser RJ, Mammel MC, Hall DC, Pappagallo M, Sardesai S, Strain JD, Baier M, Abman SH 2006 Early inhaled nitric oxide therapy in premature newborns with respiratory failure. N Engl J Med 355:354-364

19. Jaillard S, Elbaz F, Bresson-Just S, Riou Y, Houfflin-Debarge V, Rakza T, Larrue B, Storme L 2004 Pulmonary vasodilator effects of norepinephrine during the development of chronic pulmonary hypertension in neonatal lambs. Br J Anaesth 93:818824

20. Perez-de-Sa V, Cunha-Goncalves D, Nordh A, Hansson S, Larsson A, Ley D, Fellman V, Werner O 2009 High brain tissue oxygen tension during ventilation with $100 \%$ oxygen after fetal asphyxia in newborn sheep. Pediatr Res 65:57-61

21. Marks KA, Mallard EC, Roberts I, Williams CE, Sirimanne ES, Johnston B, Gluckman PD, Edwards AD 1996 Delayed vasodilation and altered oxygenation after cerebral ischemia in fetal sheep. Pediatr Res 39:48-54

22. Kinsella JP, Parker TA, Davis JM, Abman SH 2005 Superoxide dismutase improves gas exchange and pulmonary hemodynamics in premature lambs. Am J Respir Crit Care Med 172:745-749

23. Soul JS, Hammer PE, Tsuji M, Saul JP, Bassan H, Limperopoulos C, Disalvo DN, Moore M, Akins P, Ringer S, Volpe JJ, Trachtenberg F, du Plessis AJ 2007 Fluctuating pressure-passivity is common in the cerebral circulation of sick premature infants. Pediatr Res 61:467-473

24. Nagdyman N, Fleck T, Bitterling B, Ewert P, Abdul-Khaliq H, Stiller B, Hubler M, Lange PE, Berger F, Schulze-Neick I 2006 Influence of intravenous sildenafil on cerebral oxygenation measured by near-infrared spectroscopy in infants after cardiac surgery. Pediatr Res 59:462-465

25. Lassus P, Turanlahti M, Heikkila P, Andersson LC, Nupponen I, Sarnesto A, Andersson S 2001 Pulmonary vascular endothelial growth factor and Flt-1 in fetuses, in acute and chronic lung disease, and in persistent pulmonary hypertension of the newborn. Am J Respir Crit Care Med 164:1981-1987

26. McLaughlin VV, Genthner DE, Panella MM, Hess DM, Rich S 1999 Compassionate use of continuous prostacyclin in the management of secondary pulmonary hypertension: a case series. Ann Intern Med 130:740-743 
27. Leuchte HH, Schwaiblmair M, Baumgartner RA, Neurohr CF, Kolbe T, Behr J 2004 Hemodynamic response to sildenafil, nitric oxide, and iloprost in primary pulmonary hypertension. Chest 125:580-586

28. Zwissler B, Kemming G, Habler O, Kleen M, Merkel M, Haller M, Briegel J, Welte M, Peter K 1996 Inhaled prostacyclin (PGI2) versus inhaled nitric oxide in adult respiratory distress syndrome. Am J Respir Crit Care Med 154:1671-1677

29. Riva CM, Morganroth ML, Ljungman AG, Schoeneich SO, Marks RM, Todd RF III, Ward PA, Boxer LA 1990 Iloprost inhibits neutrophil-induced lung injury and neutrophil adherence to endothelial monolayers. Am J Respir Cell Mol Biol 3:301309

30. Benedict N, Seybert A, Mathier MA 2007 Evidence-based pharmacologic management of pulmonary arterial hypertension. Clin Ther 29:2134-2153

31. North AJ, Brannon TS, Wells LB, Campbell WB, Shaul PW 1994 Hypoxia stimulates prostacyclin synthesis in newborn pulmonary artery endothelium by increasing cyclooxygenase-1 protein. Circ Res 75:33-40

32. de Clety SC, Decell MK, Tod ML, Sirois P, Gordon JB 1998 Developmental changes in synthesis of and responsiveness to prostaglandins I2 and E2 in hypoxic lamb lungs. Can J Physiol Pharmacol 76:764-771
33. Zenge JP, Rairigh RL, Grover TR, Storme L, Parker TA, Kinsella JP, Abman SH 2001 NO and prostaglandin interactions during hemodynamic stress in the fetal ovine pulmonary circulation. Am J Physiol Lung Cell Mol Physiol 281:L1157L1163

34. Abel FL, Zhao RR, Bond RF 1992 Contribution of extravascular compression to reduction of maximal coronary blood flow. Am J Physiol 262:H68-H77

35. Barrington KJ, Finer NN, Peliowski A, Etches PC, Graham AJ, Chan WK 1995 Inhaled nitric oxide improves oxygenation in piglets with meconium aspiration. Pediatr Pulmonol 20:27-33

36. Bone RC 1993 A new therapy for the adult respiratory distress syndrome. N Engl J Med 328:431-432

37. Aburawi EH, Berg A, Pesonen E 2009 Effects of ballon valvuloplasty on coronary blood flow in neonates with critical pulmonary valve stenosis assessed with transthoracic doppler echocardiography. J Am Soc Echocardiogr 22: $165-169$

38. Downey JM, Kirk ES 1974 Distribution of the coronary blood flow across the canine heart wall during systole. Circ Res 34:251-257 